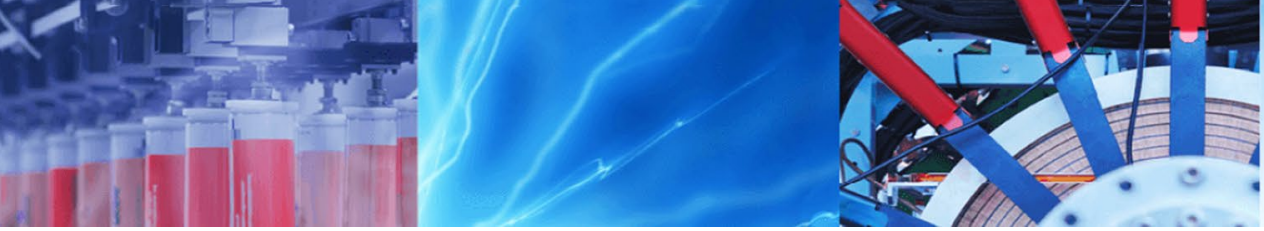

Research Article

\title{
New Brazilian pineapple leaf fibers for textile application: cottonization and dyeing performance
}

\author{
Rayana Santiago de Queiroz ${ }^{1,2} \cdot$ Ana Patrícia Veiga da Silva ${ }^{2}$ Ana Cristina da Luz Broega ${ }^{2}$. \\ António Pedro Garcia Valadares Souto ${ }^{2}$
}

Received: 4 July 2019 / Accepted: 5 December 2019 / Published online: 12 December 2019

(c) Springer Nature Switzerland AG 2019

\begin{abstract}
This work evaluates the dyeing performance associated with a cottonization and bleaching pretreatment of pineapple leaf fibers from two different species from Brazil: curaua (A. lucidus syn. A. erectifolius) and red pineapple (A. bracteatus (Lindl.) Schult. \& Schult.f), aiming its application in textile materials for garments. Treated and untreated fibers were compared for their morphological, chemical, physical and color properties. The fibers underwent changes in their chemical and physical structural characteristics after pretreatment. The results of SEM, FTIR and whiteness index analysis indicated that the cottonization process improved the color and surface uniformity of fibers, reducing non-cellulosic matters, such as lignin and pectin. Treated fibers also presented low impurities content, i.e., oils, wax and fats (between 1.1 and 2.1\%). However, compared to untreated fibers, treated curaua show an increase in impurities, supposedly caused by the removal of epidermal tissue from the fiber surface, which became the fiber bundle structure more accessible. Cottonization process also produced thinner, individualized and more resistant fiber bundles, which was evidenced by a decrease in linear density by 30 and $42 \%$ and an increase in tenacity by 12 and $23 \%$. The dyeing behavior of fibers was investigated using blue, red and yellow reactive dyes. Fibers of both species demonstrated good dyeing behavior, with $K / S$ values compatible with textile application standards (between 4 and 11) and an excellent color fastness to laundering.
\end{abstract}

Keywords Pineapple leaf fiber · Dyeing performance $\cdot$ Cottonization

\section{Introduction}

Social and environmental issues have emerged in global scale from the prevailing logics of production and consumption recurrent in the fashion system. The textile industry, one of the oldest and largest industries of the world, has become a major factor in large-scale consumption and in the misuse of natural resources throughout its evolution. This is due not only to the fact that textiles are among the main essential items, but also because of their diversification of applications over the last 60 years, as for example the technical textiles. In addition to the applications expansion, the rapid demographic and economic growth configures a scenario of growing discrepancy between fiber supply and demand, a phenomenon that Scheffer [1] refers to as a "fiber gap." According to the author, by 2020 global fiber consumption will have reached 110 million tons, which gives fiber the second place in the scale of major items, second only to food sector [2].

In this sense, natural fibers have been gaining an expressive role as an alternative to man-made oil-based fibers, not only for textile but also in several applications [3]. Unlike synthetic fibers, which are widely used in textile

$\triangle$ Rayana Santiago de Queiroz, rayanasq@ipt.br; rayanasq@gmail.com | ${ }^{1}$ Textile Technology Laboratory, Institute for Technological Research, São Paulo, Brazil. ²Department of Textile Engineering, 2C2T - Centro de Ciência e Tecnologia Têxtil, University of Minho, Guimarães, Portugal. 
industry, natural fibers are biodegradable and its cultivation usually does not cause damages to ecosystems [4]. They can add more value to the products and provide socio-environmental advantages when associated with alternative practices of production [5].

Over the last few years, some vegetable non-conventional fibrous species have been studied, allowing the development of new textile materials, and even rescuing fibers used in the past, but with a novel added value. These are among the group of fibers that Fletcher [5] denominates as "alternative fibers," which include both the development of better production practices of conventional natural fibers, and introduction of different lower-impact fiber sources, such as Lotus fibers from Nelumbo nucifera plant $[6,7]$, nettle fibers from Urtica dioica plant [8] and pineapple fibers from Ananas comosus plant $[7,9]$.

Brazilian biodiversity, which holds the most diverse flora on the planet $[10,11]$, can be a rich source of potential fibrous materials. The Bromeliaceae family is particularly important in the quantity of fibrous plants [12], and it is notorious for embracing species from Ananas genus, a known source of pineapple leaf fibers (PALFs). PALFs are widely studied as to their applicability as composites reinforcement, especially because their high mechanical properties [13-16], but its textile application in garment industry still little investigated.

The investigation of the applicability of new vegetable fibers for textile production requires determination of several characteristics, which includes besides morphological, dimensional, chemical and mechanical properties, the evaluation of their behavior in different conditions of processing and use depending of the end use. In the case of textiles for garments, the evaluation of the dyeability is essential to verify the viability of these fibers.

In this work, dyeing behavior of two Brazilian PALFs species was studied after a cottonization pretreatment. The structural, chemical and mechanical properties of treated and untreated fibers were measured. Dyed fibers were also evaluated for their colorimetric and color fastness properties.

\section{Experimental}

\subsection{Fibers: gathering and processing}

The samples of leaves fibers were taken from two botanical species of the genus Ananas (Bromeliaceae family): curaua (Ananas lucidus Mill. syn. Ananas erectifolius L.B.Sm.) and red pineapple (Ananas bracteatus (Lindl.) Schult. \& Schult.f). Curaua fibers, extracted by mechanical process, were provided by Center of de Biotechnology of Amazonia-CBA and red pineapple fibers were manually extracted, with the help of tweezers, from fresh leaves collected in a rural area in countryside of Sao Paulo state (Brazil) located at $23^{\circ} 32^{\prime} 37.6^{\prime \prime} \mathrm{S} 48^{\circ} 14^{\prime} 11.6^{\prime \prime} \mathrm{W}$.

\subsection{Cottonization pretreatment}

Mandatorily, finishing process like dyeing and printing in cellulosic fibers, yarns and fabrics requires some pretreatments, namely scouring and bleaching, to remove natural and added impurities, aiming to improve their absorbency and satisfactory whiteness to receive the color [17]. Cottonization is a process quite applied for flax and hemp fibers. The main purpose of this pretreatment is to reduce the level of fiber impurities, making them thinner, shorter and softer, and thus compatible with cotton or wool spinning systems and blends with artificial fibers. There are several methods of cottonization: chemical, enzymatic, by using ultrasound or steam explosion methods $[18,19]$. Therefore, in order to optimize fibers surface properties, reducing their impurities content and reach a satisfactory degree of whiteness before the dyeing process, both PALFs were cottonized according with method suggested by Andrassy, Pezelj and Šurina [20], in which the ultrasound treatment is combined with a bleaching solution. The advantage of this method is that bleaching can be achieved simultaneously with cottonization, ensuring fibers ready to be dyed, reducing energy consumption and amount of chemicals used [20]. Parameters used in this pretreatment are tabulated in Table 1. After the pretreatment, fibers were rinsed in running water and then dried at room temperature.

\subsubsection{Morphological analysis by scanning electron microscopy (SEM)}

The morphological characterization of treated and untreated sample fibers was performed by scanning electron microscopy (SEM). The aim was to analyze the fibers

Table 1 Pretreatment parameters

\begin{tabular}{ll}
\hline Parameters & Amount \\
\hline Bath ratio & $1: 10$ \\
Temperature & $80{ }^{\circ} \mathrm{C}$ \\
Ultrasound frequency & $30 \mathrm{kHz}$ \\
Time & $30 \mathrm{~min}$ \\
Bleaching solution & \\
Hydrogen peroxide $\left(\mathrm{H}_{2} \mathrm{O}_{2}\right)$ & $20 \mathrm{~mL} / \mathrm{L}$ \\
Sodium hydroxide $\left(\mathrm{NaOH}^{\prime}\right)$ & $12 \mathrm{~mL} / \mathrm{L}$ \\
Stabilizer Baystabi $\mathrm{DB}$ & $4 \mathrm{~g} / \mathrm{L}$ \\
Wetting agent Diadavin ${ }^{\oplus} \mathrm{UN}$ & $1 \mathrm{~g} / \mathrm{L}$ \\
\hline
\end{tabular}


surface morphology, identifying the effects of the cottonization on surface modification.

\subsubsection{Impurities content}

Impurities content of treated and untreated sample fibers was determined by removal non-fibrous matter method, based in the general guidelines of Annex A of ISO 1833-1: 2006 standard. Extraction was carried out with light petroleum for $5 \mathrm{~h}$.

\subsubsection{Fourier transform-infra red spectroscopy (FTIR)}

The FTIR spectra of treated and untreated sample fibers were recorded on an attenuated total reflection Fourier transform infrared (ATR-FTIR), with 32 scans in spectral range of $4000-400 \mathrm{~cm}^{-1}$ at a resolution of $4 \mathrm{~cm}^{-1}$.

\subsubsection{Linear density}

Linear density (tex) of treated and untreated sample fibers was determined based on gravimetric method of ISO 1973: 1995 standard test method. Ten test specimens, each composed of a bundle of 50 individual fibers of $50 \mathrm{~mm}$ length, were weighed, and linear density was calculated using Eq. (1):

$D_{\mathrm{L}}=\frac{m_{\mathrm{f}}}{n_{\mathrm{f}} \times L_{\mathrm{f}}} \times 10000$

where $D_{\mathrm{L}}=$ linear density in dtex, $m_{\mathrm{f}}=$ mass of fiber bundle in $\mathrm{mg}, n_{\mathrm{f}}=$ number of fibers per bundle, and $L_{\mathrm{f}}=$ length of fibers.

\subsubsection{Tensile properties}

Tensile properties (breaking force, breaking tenacity and elongation) of treated and untreated sample fibers were determined in a constant-rate-of-extension (CRE) type tensile testing machine, based on standard test method ASTM D3822:2014. Twenty test specimens were tested with $30 \mathrm{~mm}$ of gauge length and $3 \mathrm{~mm} / \mathrm{min}$ of rate of extension.

Breaking tenacity of individual specimens was calculated based in linear density of each fiber sample, using Eq. (2):

$Y=\frac{F}{D_{\mathrm{L}}}$

where $Y=$ breaking tenacity in $\mathrm{cN} /$ tex, and $F=$ breaking force in $\mathrm{CN} D_{\mathrm{L}}=$ linear density in tex.

\subsubsection{Whiteness index (WI)}

Treated undyed fiber samples were evaluated in spectrophotometer using illuminant D65, small area view $\left(\approx 34 \mathrm{~mm}^{2}\right)$, specular included and $10^{\circ}$ observer. The aim of this analysis was to verify the effect of bleaching process performed together with cottonization. The WI was determined based on Berger formulae Eq. (3):

$\mathrm{WI}_{\text {Berger }}=Y+3.108 Z-3.831 X$

where $X, Y, Z$ are the CIE tristimulus values.

\subsection{Dyeing experiment}

In order to check dyeability of curaua and red pineapple fibers, cottonized fiber samples were dyed by exhaustion, according with curve process mentioned in Fig. 1 and using a fluorine-based reactive dye, namely Levafix ${ }^{\circledast}$ blue, red and yellow dye. Samples of fibers were prepared with $1 \mathrm{~g}$ each. The bath ratio used in the dyeing process was 20:1. The dyeing baths of $20 \mathrm{~mL}$ each were prepared with $0.01 \mathrm{~g}$ of dyestuff, $0.7 \mathrm{~g}$ of sodium chloride $(\mathrm{NaCl})$ and sodium carbonate $\left(\mathrm{Na}_{2} \mathrm{CO}_{3}\right)$. After dyeing, the samples were rinsed under running water to remove the salt and the alkali, and then, they were washed in a boiling $2 \mathrm{~g} / \mathrm{L}$ detergent solution (Wetting agent Diadavin ${ }^{\circledR} \mathrm{UN}$ ) for $15 \mathrm{~min}$ and dried at room temperature. Parameters of dyeing are tabulated in Table 2.

\subsubsection{Reflectance $(R \%)$ and color strength $(K / S)$}

In order to verify the behavior of fibers to the dyeing, the dyed fibers samples were evaluated for the reflectance $(R \%)$ and color strength $(K / S)$ properties. The reading was performed on a spectrophotometer using the illuminant $D 65$, small area view $\left(\approx 34 \mathrm{~mm}^{2}\right)$, including specular and $10^{\circ}$ observer. Color strength $(K / S)$ is represented by Kubelka-Munk theory [21-23] Eq. (4):

$\frac{K}{S}=\frac{(1-R)^{2}}{2 R}$

where $R=$ reflected light, $K=$ coefficient of absorption, and $S=$ coefficient of scattering.

\subsubsection{Color fastness to laundering}

Color fastness of dyed fiber samples was evaluated for their wash fastness properties (color change and staining), according to standard test method ISO 105-C06:2010 (method A1S), using ECE phosphate reference detergent without optical brightener. The assessment of color change and staining degree was performed based on 


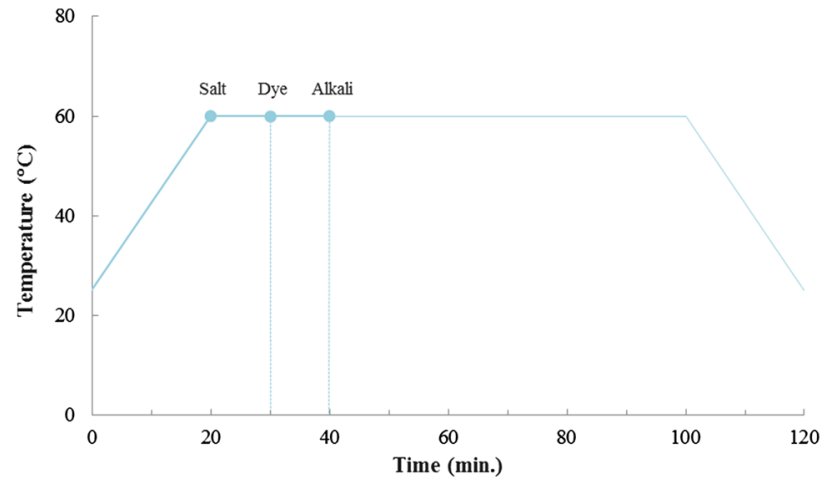

Fig. 1 Process curve of reactive dyeing

Table 2 Dyeing parameters

\begin{tabular}{ll}
\hline Parameters & Amount \\
\hline Bath ratio & $20: 1$ \\
Temperature & $60{ }^{\circ} \mathrm{C}$ \\
Time & $120 \mathrm{~min}$ \\
Reagents & \\
Soda ash $\left(\mathrm{Na}_{2} \mathrm{CO}_{3}\right)$ & $35 \mathrm{~g} / \mathrm{L}$ \\
Sodium chloride $(\mathrm{NaCl})$ & $10 \mathrm{~g} / \mathrm{L}$ \\
Levafix ${ }^{\oplus}$ Blue CA & $1 \%{ }^{*}$ \\
Levafix ${ }^{\oplus e d} \mathrm{CA}$ & $1 \%{ }^{*}$ \\
Levafix ${ }^{\oplus}$ Yellow CA & $1 \% *$ \\
\hline
\end{tabular}

*Based on the fibers weight

the gray scale, from grades 1-5 (with four half steps), of which grade 5 represents no change/staining and grade 1 depicts severe change/staining.

\section{Results and discussion}

\subsection{Effect of pretreatment on fibers characteristics}

As previously mentioned, cottonization process aims mainly modify some fiber surface attributes, making the fibers more regular, lower fineness and better to touch, thanks to reducing the fibers impurities. When associated with a bleaching solution, it was also expected a whitening and color homogenization.

As can be seen in Fig. 2, the curaua fibers in the natural condition, prior to the pretreatment process, have a natural more yellowish color and a more rigid appearance than the fibers of the red pineapple. This difference can be attributed to the nature of each plant species, but also to the plant maturity and the method in which the fibers were extracted [12]. Thus, due to the significantly yellowing shade of the curaua fiber samples, it was necessary to repeat the pretreatment process to achieve a visually satisfactory degree of whiteness, resulting in whiter fibers than the second, from which the procedure was performed only once.

\subsubsection{Morphological characteristics}

Scanning electron microscopy (SEM) technique is commonly used to study surface morphology of fibers and fiber bundles, being suitable for visual evaluation of differences between fibers [24]. According to the SEM images of treated and untreated fibers (Figs. 3 and 4), it is possible to observe that the cottonization process improved the surface uniformity of both PALF, removing residual noncellulosic materials.

Figures 3c, e, and 4c, e, show the presence of leaf epidermal tissue fragments on the surface of untreated fibers, which is characterized by a reticular aspect pattern. After pretreatment (Figs. $3 d, f, 4 d, f$ ), this structure is no longer observed.

The cottonization process also caused a reduction in the diameter of bundle fibers, with smaller number of fibers per bundle, which can be better evidenced by the linear density results. When comparing the curaua and red pineapple fibers, it is noticed that fibers extracted from red pineapple leaves, both before and after the pretreatment, presented more individualized in the bundle, whereas curaua fibers remained more linear and united, giving a harder and more compact appearance.

\subsubsection{Impurities content}

Impurities content is a quantity indicator of the effectiveness of pretreatment. Pretreatment is expected to reduce the impurity content of the raw fibers. However, nonfibrous matter content (more specifically oils, waxes and fats) of curaua fibers shows an increase (about 1.26\%) after pretreatment (Table 3). This can be explained by effect of removal of first layer of epidermal tissue from the fiber surface, which became the fiber bundle structure more accessible.

On the other hand, treated red pineapple fibers had a $0.39 \%$ reduction in non-fibrous matter content over untreated fibers.

Even so, it can be considered that both PALF, with and without pretreatment, indicated low impurities content.

\subsubsection{Fourier transform-infra red spectroscopy (FTIR)}

FTIR is the most widely available spectroscopic technique used to characterize fibers and investigate their chemical transformations at molecular level. 
Fig. 2 Visual aspect of fibers before and after pretreatment

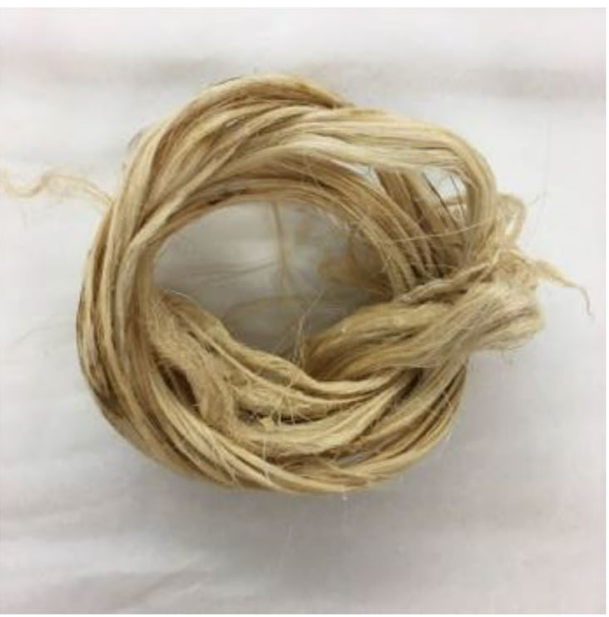

a Untreated Curaua fibers

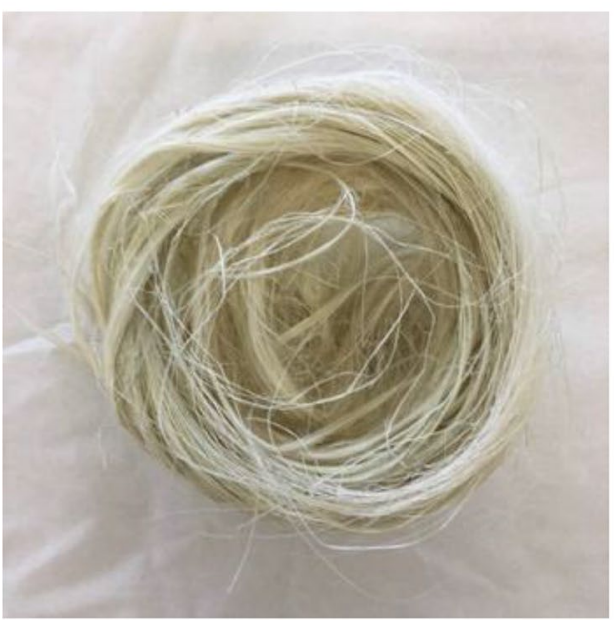

c Untreated Red pineapple fibers

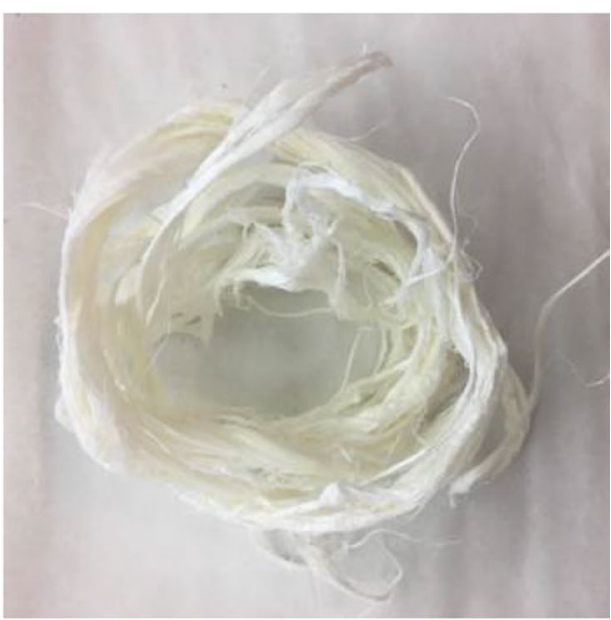

b Treated Curana fibers

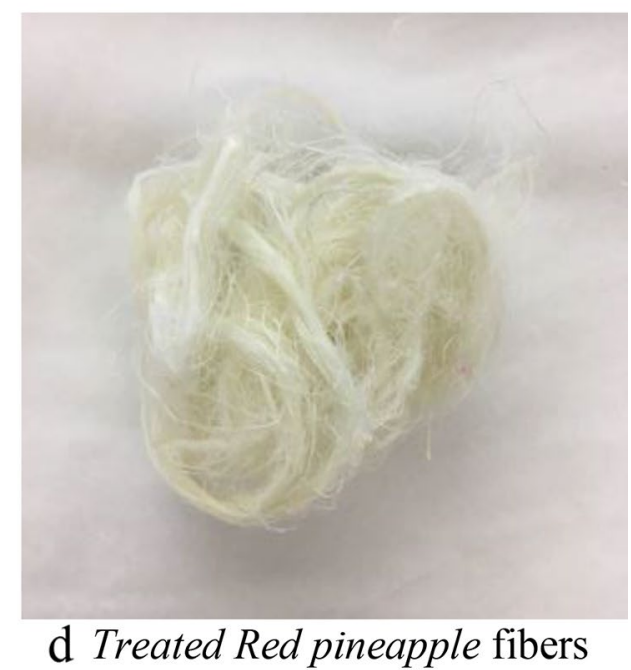

Figure $5 a$, $b$ shows the FTIR of PALF samples before and after pretreatment. The FTIR spectra of the both untreated PALF showed similar shapes, typical of lignocellulosic fibers [25] and similar to other PALF species studied by Sena Neto et al. [14].

The $3330 \mathrm{~cm}^{-1}$ band observed in the spectra corresponds to the hydrogen bonds for cellulose and hemicellulose [26, 27]. The peaks wave numbers of 2920 and $2850 \mathrm{~cm}^{-1}$ are attributed to the $\mathrm{C}-\mathrm{H}$ stretching of saturated alkane for wax [26]. The peak at $1737 \mathrm{~cm}^{-1}$ corresponds to the acetyl groups and $\mathrm{C}-\mathrm{O}$ bonds, characteristic of the hemicellulose and also affected by the presence of pectin $[14,26]$. The lignin is characterized by the bands of $1601 \mathrm{~cm}^{-1}, 1425 \mathrm{~cm}^{-1}, 1374 \mathrm{~cm}^{-1}, 1243 \mathrm{~cm}^{-1}$ and $1035 \mathrm{~cm}^{-1}$ [26]. Finally, the bands of $1160 \mathrm{~cm}^{-1}, 1105 \mathrm{~cm}^{-1}$, $1053 \mathrm{~cm}^{-1}$ and $898 \mathrm{~cm}^{-1}$ also observed are related to the presence of cellulose and hemicellulose [26].

Analyzing the chemical transformations before pretreatment was observed a reduction in peaks at $1236 \mathrm{~cm}^{-1}$ (curaua) and $1248 \mathrm{~cm}^{-1}$ (red pineapple), which indicate a degradation of lignin. Peaks at $1737 \mathrm{~cm}^{-1}$ (curaua) and $1734 \mathrm{~cm}^{-1}$ (red pineapple), attributed to the acetyl and ester linkages in hemicelluloses and pectin, also presented reduction. Curaua fibers also showed transformations in the $3330 \mathrm{~cm}^{-1}, 2900 \mathrm{~cm}^{-1}, 1103 \mathrm{~cm}^{-1}$ and $898 \mathrm{~cm}^{-1}$ band, related to cellulose and hemicellulose, which were more defined after pretreatment. There was also a reduction in wax-related peaks of 2920 and $2850 \mathrm{~cm}^{-1}$. These changes can be attributed to the removal of epidermal tissue from the fiber surface that kept the fiber bundle structure closer. After pretreatment, the fibers were more individualized leaving the cellulose and hemicellulose layer more exposed. This also explains the increased impurity content of curaua fibers after pretreatment.

\subsubsection{Linear density}

Linear density is a property related to fiber fineness and intrinsic mass. Since most natural fibers have an irregular diameter along their length, determining linear density 


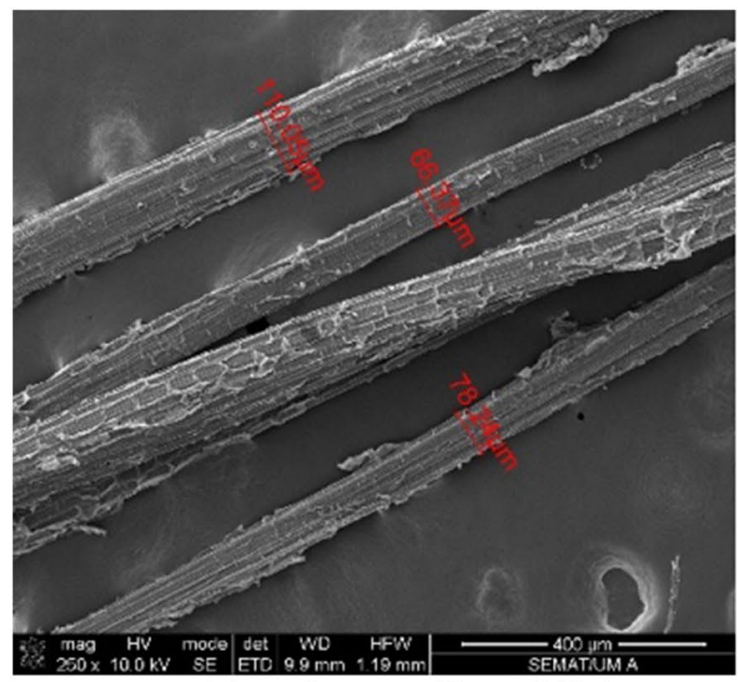

a Natural curana fibers (250x)

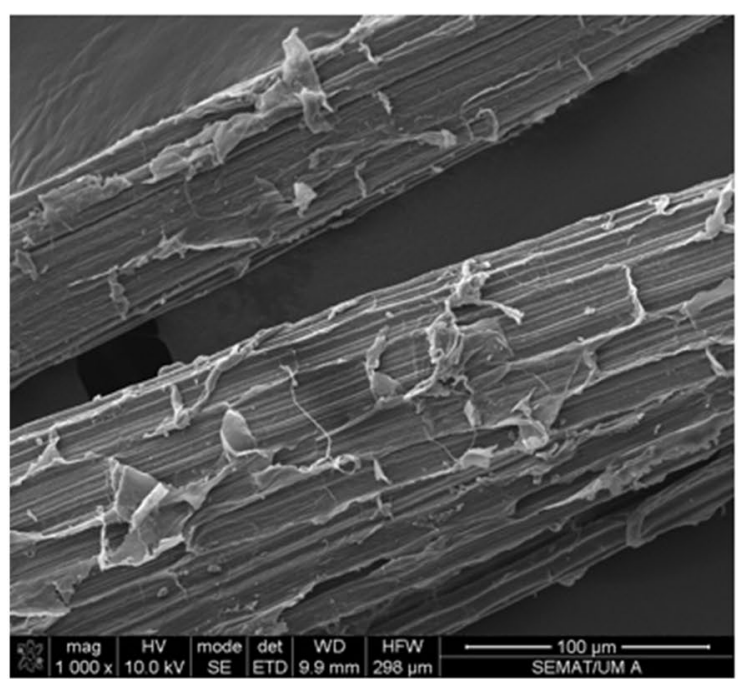

c Natural curaua fibers $(1000 \mathrm{x})$

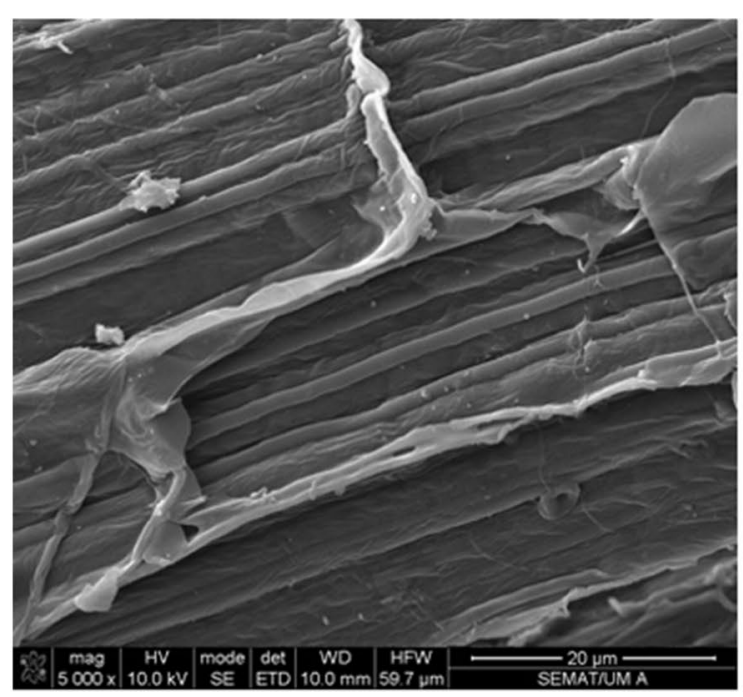

e Natural curaua fibers (5 000x)

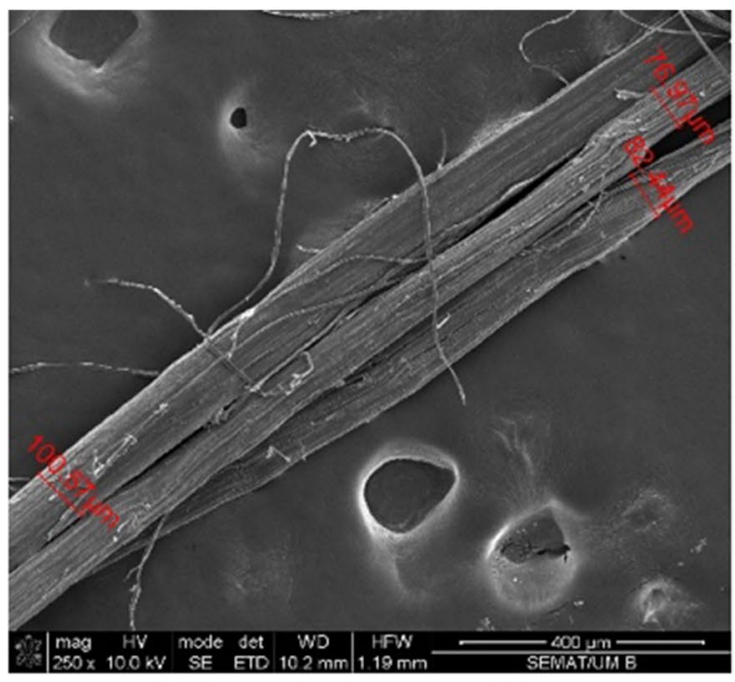

b Cottonized curana (250x)

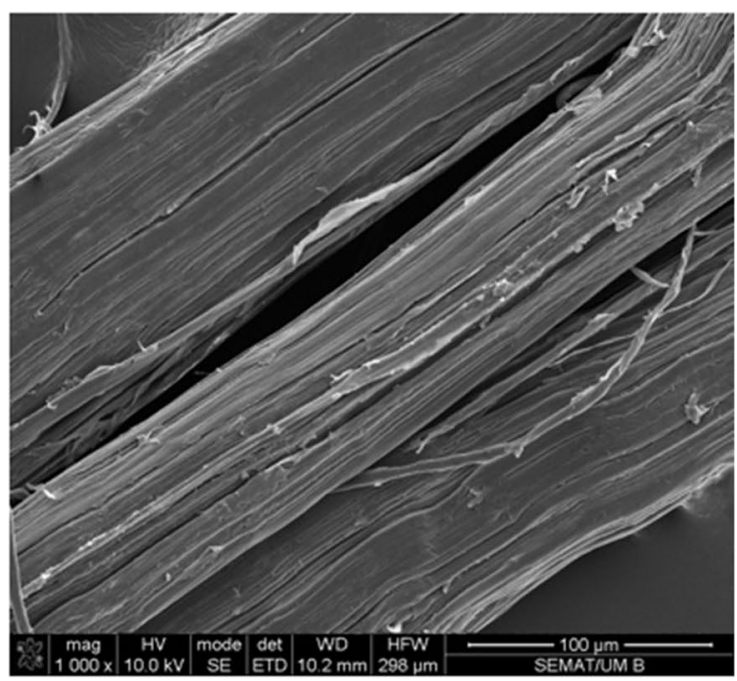

d Cottonized curaua $(1000 x)$

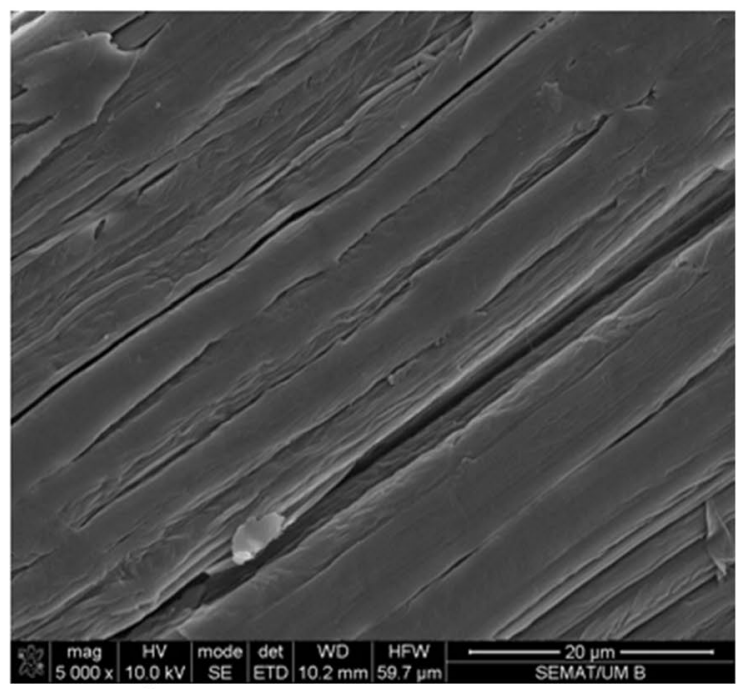

f Cottonized curaua (5 000x)

Fig. 3 Curaua SEM images before and after cottonization

\section{SN Applied Sciences}

a SPRINGER NATURE journal 


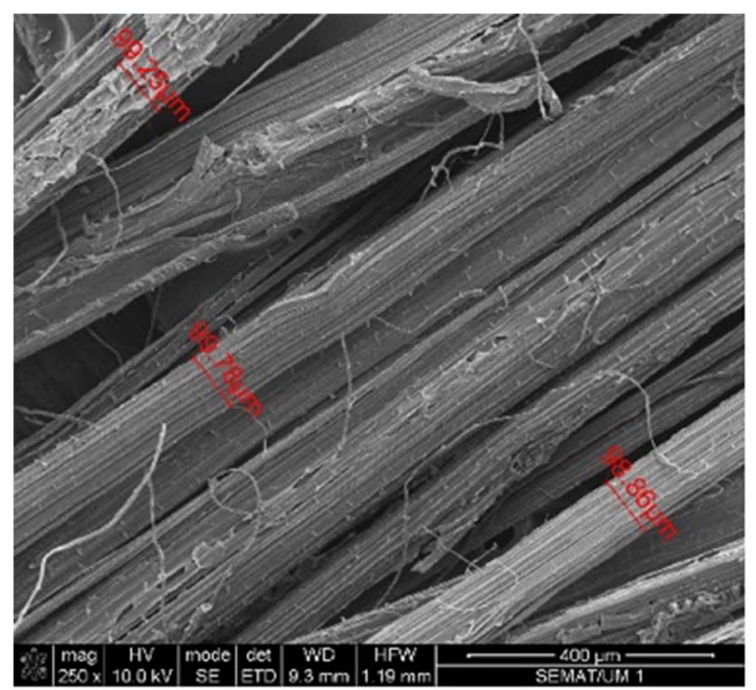

a Natural red pineapple fibers (250x)

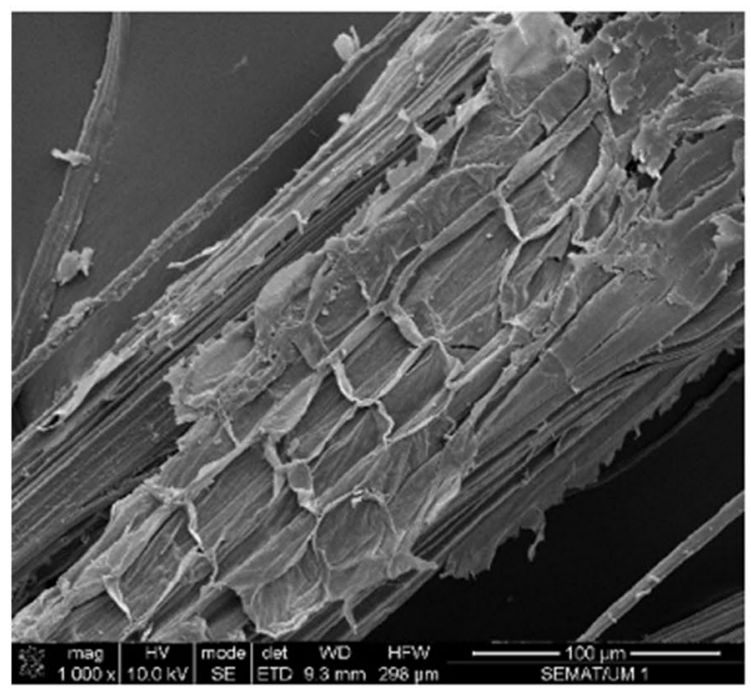

c Natural red pineapple fibers (1000x)

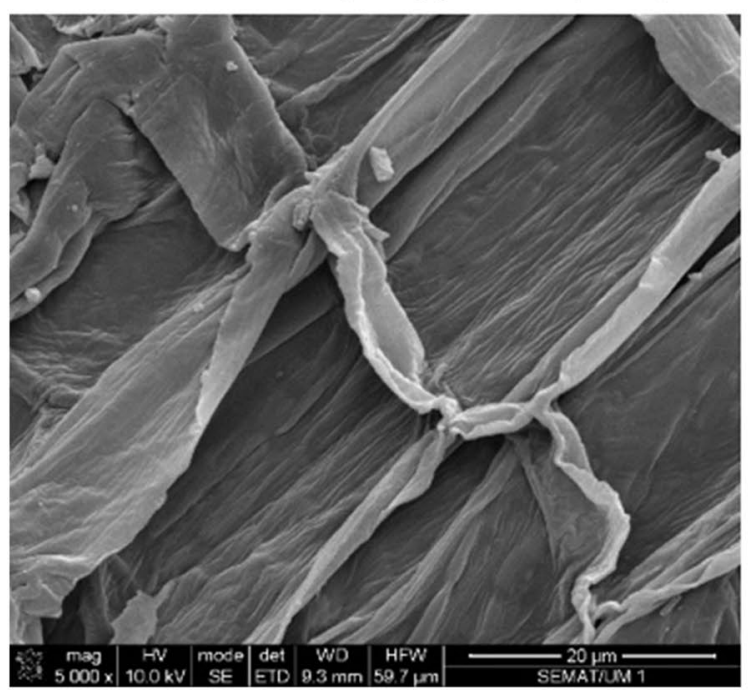

e Natural red pineapple fibers (5000x)

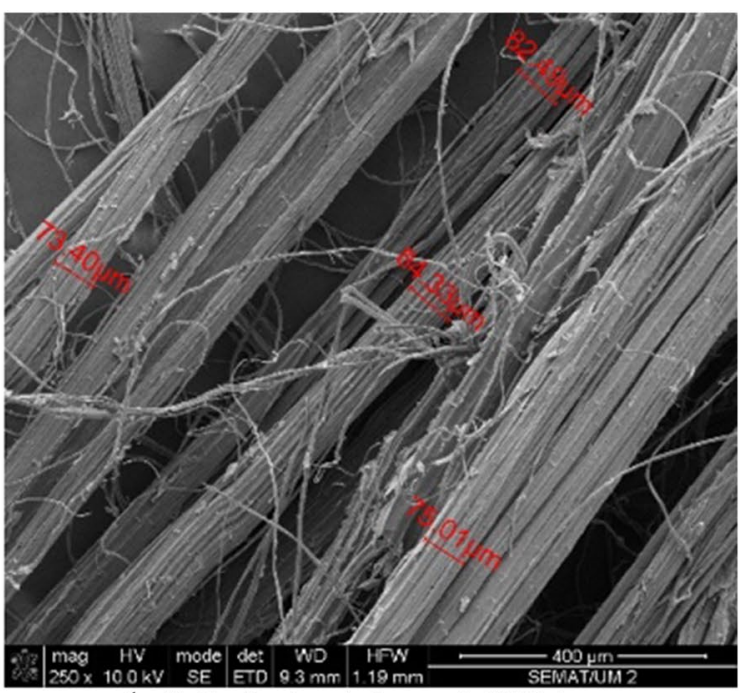

b Cottonized red pineapple (250x)

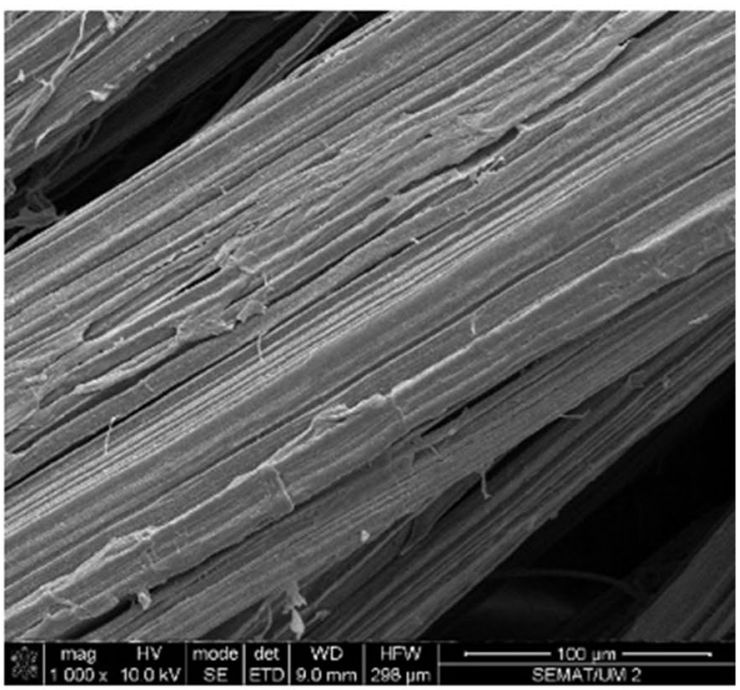

$\mathrm{d}$ Cottonized red pineapple $(1000 \mathrm{x})$

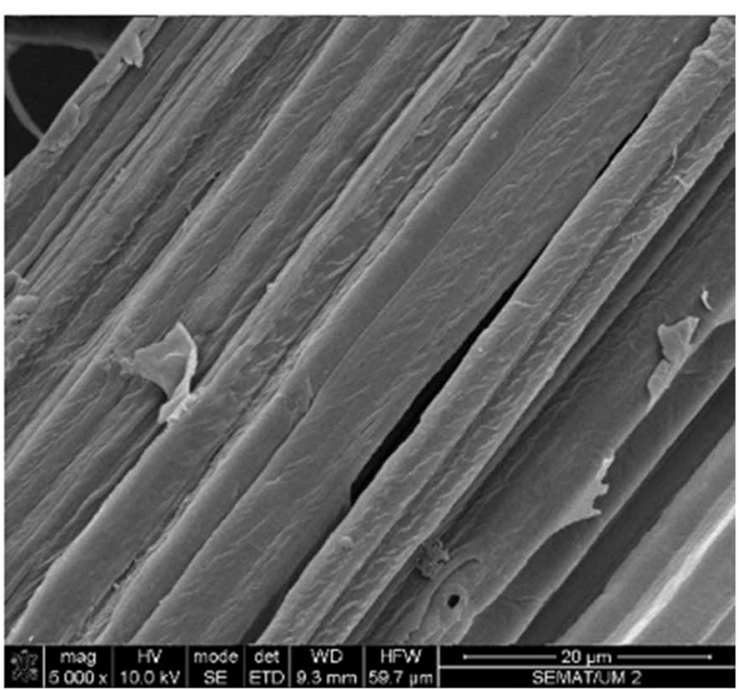

f Cottonized red pineapple (5000x)

Fig. 4 Red pineapple SEM images before and after cottonization 
Table 3 Impurities content of treated and untreated fibers

\begin{tabular}{lll}
\hline Condition & \multicolumn{2}{l}{ Non-fibrous matter content (\%) } \\
\cline { 2 - 3 } & $\begin{array}{l}\text { Ananas erectifolius } \\
\text { (curaua) }\end{array}$ & $\begin{array}{l}\text { Ananas } \\
\text { bracteatus (red } \\
\text { pineapple) }\end{array}$ \\
\hline Before cottonization & 0.85 & 1.52 \\
After cottonization & 2.11 & 1.13 \\
\hline
\end{tabular}

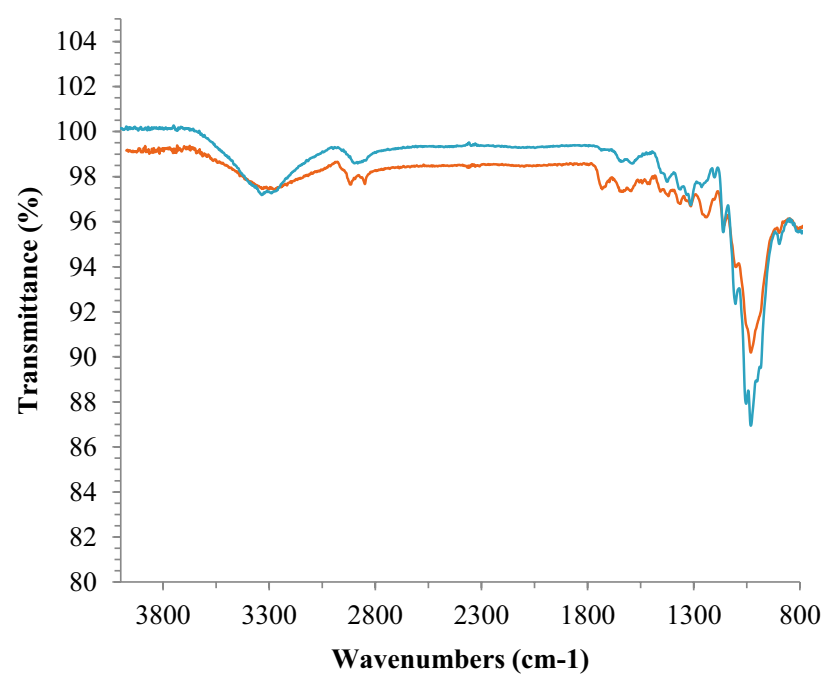

Untreated curaua fibers — Treated curaua fibers

a

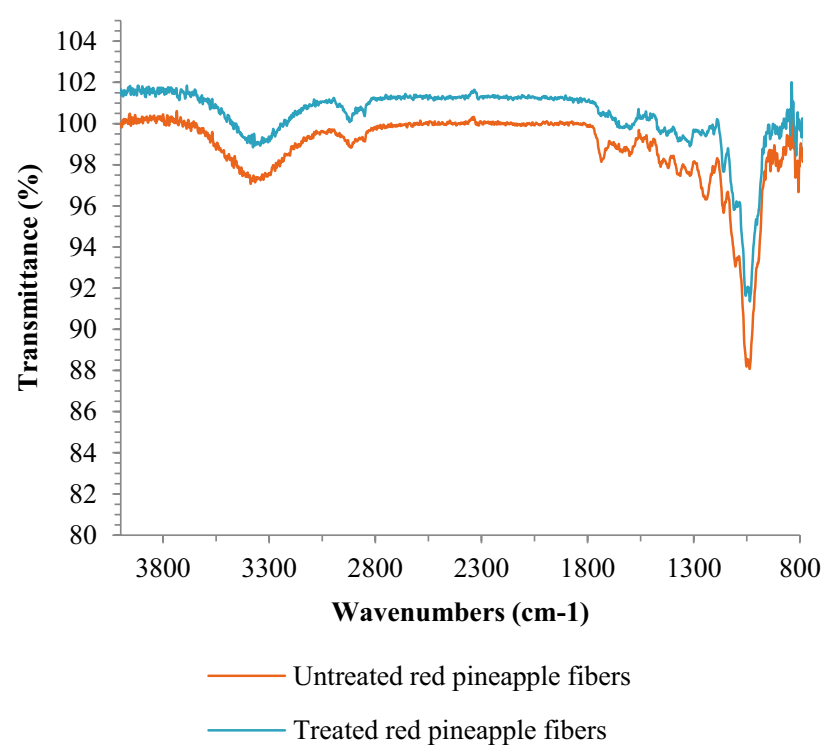

b

Fig. 5 The FITR of untreated and treated PALF samples

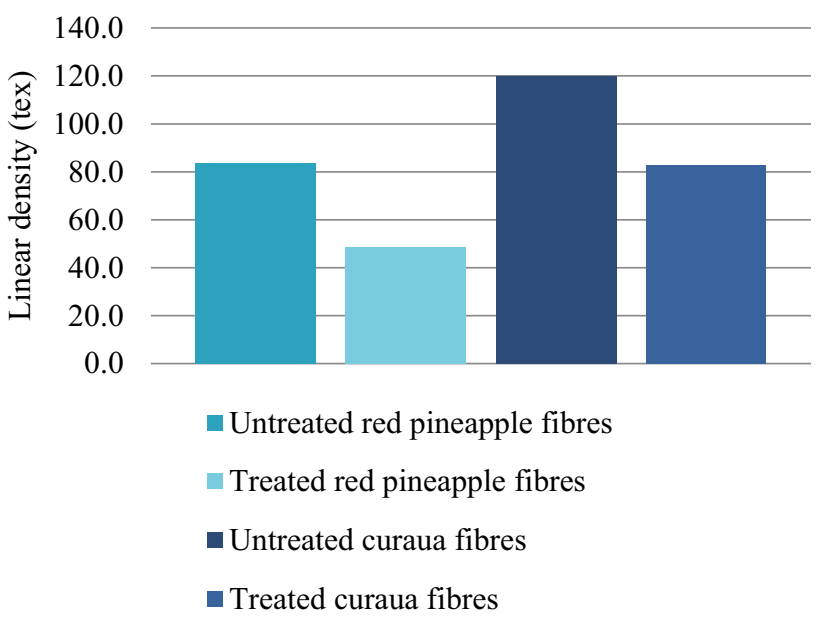

Fig. 6 Linear density of untreated and treated curaua and red pineapple fibers

is the most useful and reliable way of describing the fiber fineness and coarseness [24, 28]. In this study, this property is particular useful for observing the effects of cottonization as the changes in the diameter of fibers, also providing a quantitative indication of pretreatment efficiency. The results from Fig. 6 show that the fiber fineness after pretreatment reduced by about $30 \%$ for the curaua fibers and $42 \%$ for the red pineapple fibers. This considerable decrease in linear density for both PALFs indicates that the cottonization process allowed for better individualization of thick fiber bundles into elementary fibers and fiber bundles with lower linear density, which was also observed in the SEM images.

\subsubsection{Tensile properties}

The mechanical properties of textile fibers are probably their most important properties, especially because they affect its behavior in the processing as well as in the characteristics of the final product, being determinants for the evaluation of the textile application viability [28]. Processes such as cottonization and bleaching, which modify the structural characteristics of fibers, also alter their mechanical properties, generally reducing fiber strength. Thus, for the cottonization process to be successful, it is desirable that the reduction in fiber fineness is equal to or greater than its loss in strength, which is represented by the ratio of breaking force $(\mathrm{cN})$ to linear density (tex), also called breaking tenacity (cN/tex).

Figure 7 shows that there was a loss of fiber breaking force after pretreatment, around 21 and $28 \%$, for the curaua and red pineapple fibers, respectively. However, considering the tenacity results (Fig. 8), it is noted that this loss is not real, since the reduction in linear density 


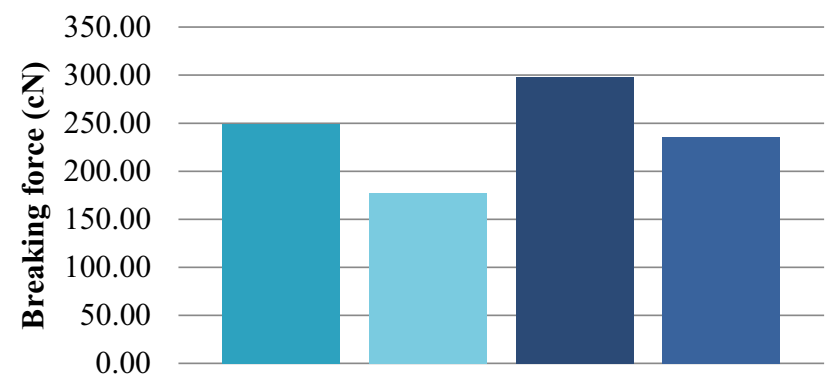

- Untreated red pineapple fibres

Treated red pineapple fibres

- Untreated curaua fibres

- Treated curaua fibres

Fig. 7 Breaking force of untreated and treated curaua and red pineapple fibers

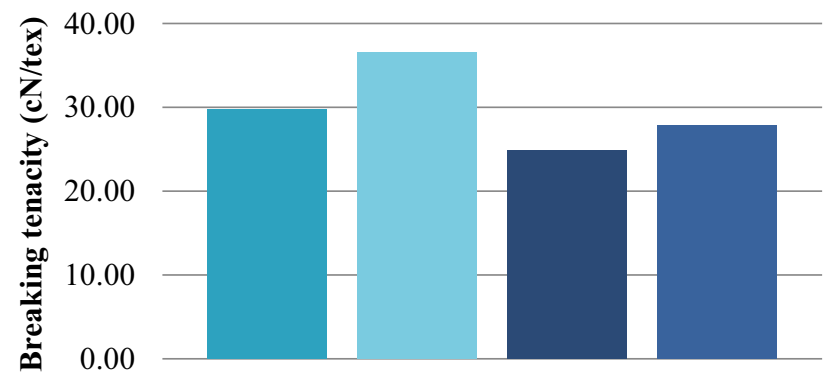

- Untreated red pineapple fibres

Treated red pineapple fibres

- Untreated curaua fibres

- Treated curaua fibres

Fig. 8 Breaking tenacity of untreated and treated curaua and red pineapple fibers

was greater than the loss of breaking force, resulting in a $12 \%$ increase in breaking tenacity for the curaua fibers and $23 \%$ for red pineapple fibers. This increase in tenacity indicates that the cottonization allowed the individualization of fiber bundles without, however, impairing its tensile strength.

Regarding to elongation at break (Fig. 9), the curaua fibers decreased by $38 \%$ after pretreatment, which can be considered a disadvantage. Even so, the $2.8 \%$ elongation resulting from the treated fibers, when compared to reference values of the literature for cotton (3-7\%), flax (1.5-4.0\%) and hemp (2.2\%) [28, 29], can still be considered acceptable. In the case of red pineapple fiber, elongation was practically the same before and after pretreatment, approximately $5.6 \%$.

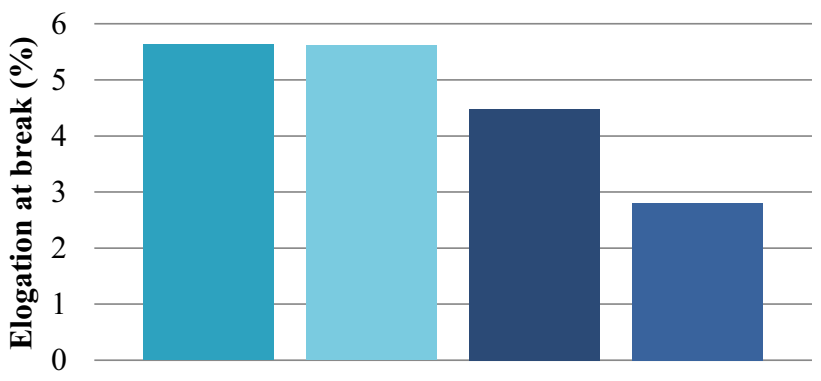

- Untreated red pineapple fibres

Treated red pineapple fibres

- Untreated curaua fibres

- Treated curaua fibres

Fig. 9 Elongation at break of untreated and treated curaua and red pineapple fibers

\subsubsection{Whiteness index (WI)}

Whiteness is defined as an attribute that indicates how close the object color is to a desired white [30]. Thanks to the presence of some impurities, fibers extracted from plants often have a yellowish appearance. In the textile industry, bleaching treatments are essential process carried out in order to obtain cleaner and lighter fibers, resulting in a more uniform raw material [31], suitable for submission of subsequent process and finishes, e.g., the dyeing. This is the reason why the whiteness degree is most often considered an important quality parameter for textile application, being a quantity indicator of the impurities degree [32].

The aim of this analysis was to verify the effect of bleaching process performed together with cottonization. Table 4 indicates the results of whiteness index evaluation of both PALF after treatment. As evidenced by visual perception, it is noted that curaua fibers WI showed to be satisfactory and was meaningly higher than red pineapple fibers $(\approx 50 \%$ superior). Comparing with hydrogen peroxide bleached cotton whiteness index values found in literature [33-35], ranging from 47 to 72 , the red pineapple fibers whiteness index was lower.

\subsection{Evaluation of PALF fibers dyeing performance}

Figure 10 shows the visual aspect of dyed PALF samples. As can be seen, both fibers showed very similar color appearance after the dyeing. In the red pineapple fibers, however, the colors became a little more intense and brilliant. 
Table 4 Whiteness index evaluation results

\begin{tabular}{lll}
\hline Condition & Whiteness index (WI) & \\
\hline After cottonization & Ananas erectifolius (curaua) & Ananas bracteatus (red pineapple) \\
& 49.5 & 33.7 \\
\hline
\end{tabular}

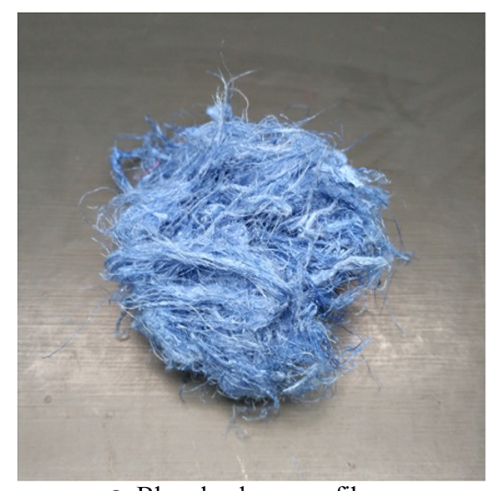

a Blue dyed curaua fibers

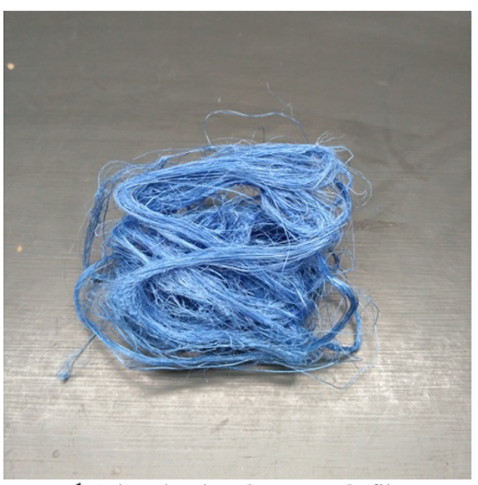

d Blue dyed red pineapple fibers

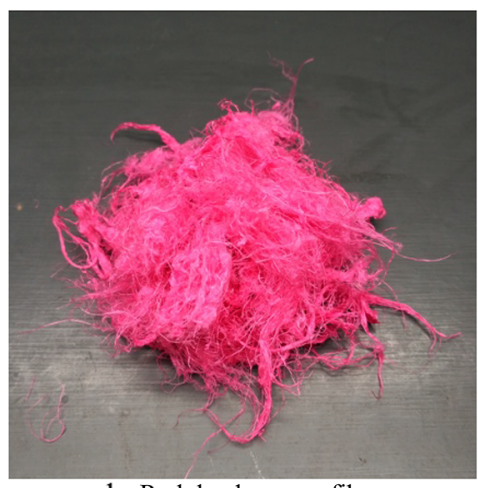

b Red dyed curaua fibers

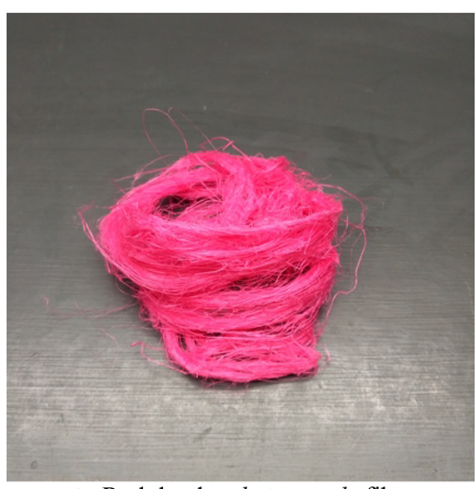

e Red dyed red pineapple fibers

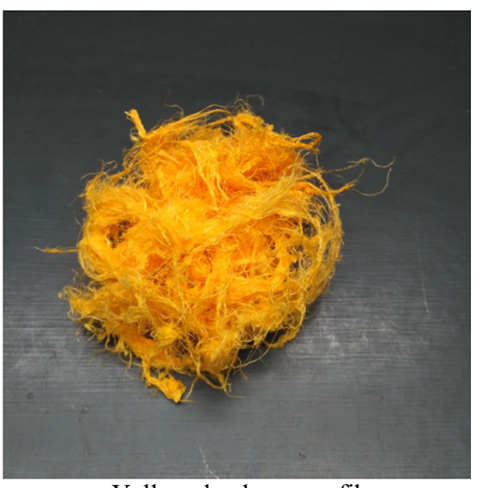

c Yellow dyed curaua fibers

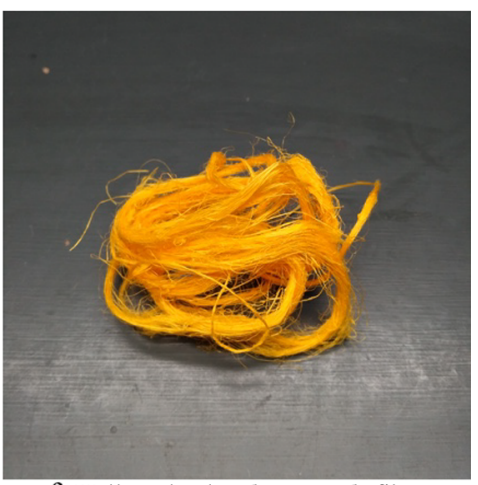

f Yellow dyed red pineapple fibers

Fig. 10 PALF fibers before dyeing experiments

Table 5 Reflectance and color strength results

\begin{tabular}{llclr}
\hline Samples & $K / S$ & $R \%$ & $K / S$ & \multicolumn{1}{c}{$R \%$} \\
& Ananas erectifolius (curaua) & $\begin{array}{l}\text { Ananas bracteatus } \\
\text { (red pineapple) }\end{array}$ \\
\hline Blue & 5.50 & 69.73 & 11.43 & 54.00 \\
Red & 4.21 & 132.55 & 8.40 & 108.84 \\
Yellow & 4.73 & 152.14 & 7.32 & 140.05 \\
\hline
\end{tabular}

\subsubsection{Reflectance $(R \%)$ and color strength $(K / S)$}

Reflectance $(R \%)$ of a material is the ratio of the reflected radiant or luminous flux of its surface to the incident flux. This property is determined by measuring the amount of light which is reflected from the material surface under a standard illuminating condition [36]. It is inversely proportional to the absorbance, which means that when the reflectance is higher, the absorbance is lower and vice versa. The color strength $(K / S)$ is also associated with absorbance property, and it is a numerical value related to the amount of dye retained in a sample, so this measure indicates how deep is the color in a dyed textile subtract.

According with results in Table 5, lesser reflectance values $R \%$ for curaua fibers revealed that the dye absorbance was better for red pineapple fibers, which was also result in a high $K / S$ value. Whereas $K / S$ values of reactive dyed cotton fabrics found in the literature may range from 4 to 16 [37-39], the $K / S$ values obtained in dyeing experiment are compatible with textile application standards and having excellent dyeing efficiency.

\subsubsection{Color fastness to laundering}

Color fastness is an important property of dyed textiles. The dyeing properties are related to the depth of the color, which depends on good molecular interaction between the inherent physical structure of the fiber and the dye and other reagents $[23,40]$. Color fastness tests assess the dyeing performance regarding the ability of a dyed material

\section{SN Applied Sciences}


Table 6 Color fastness to laundering

\begin{tabular}{llllllllll}
\hline Substrate & Dye & $\begin{array}{l}\text { Color } \\
\text { change }\end{array}$ & & \multicolumn{7}{l}{ Color staining } & & & \\
\cline { 5 - 10 } & & & & CA & CO & PA & PES & PAC & WO \\
\hline Ananas erectifolius (curaua) & Blue & 5 & 5 & 5 & 5 & 5 & 5 & 5 \\
& Red & 5 & 5 & 5 & 5 & 5 & 5 & 5 \\
& Yellow & 5 & 5 & 5 & 5 & 5 & 5 & 5 \\
Ananas bracteatus (red pineapple) & Blue & 5 & 5 & 5 & 5 & 5 & 5 & 5 \\
& Red & 5 & 5 & 5 & 5 & 5 & 5 & 5 \\
& Yellow & 5 & 5 & 5 & 5 & 5 & 5 & 5 \\
\hline
\end{tabular}

$C A$ acetate, $C O$ cotton, $P A$ polyamide, $P E S$ polyester, $P A C$ acrylic, WO wool to retain its original color and not to stain other materials when subjected to specific conditions that simulate general usage situations, such as rubbing, washing, exposure to light, contact with sweat, etc.

The grades of color change to wash assigned to the dyed PALF samples (Table 6) were all 5 (no color change). Color staining to the wash was also rating with grade 5 (no staining) for all the fibers of the multifiber adjacent fabric. Associated with the $K / S$ values, these results demonstrate that both the curaua fibers and the red pineapple fibers have good dyeability, which is another indicator of their viability in textile production.

\section{Conclusions}

The interest of new textile vegetable fibers and its performance in textile process is increasingly emerging and could be a sustainable alternative of raw material for the textile and garment industry and a possibility to optimize local resources. Studies carried out with several species native to Brazil of the Ananas genus have revealed great potential of them in production of new materials. In this paper, the textile applicability of the curaua fibers and the red pineapple was investigated focusing on their performance in dyeing process associated with a cottonization and bleaching pretreatment. Fibers were characterized for their morphological (SEM), chemical (FTIR and impurities content) and physical (linear density) structure, tensile properties as well as their dyeability.

Whereas SEM and whiteness index analysis, it was observed that cottonization and bleaching pretreatment improved the color and surface uniformity of fibers, reducing non-cellulosic matters. Impurities content (oils, wax and fats) of fibers is relatively low: 0.85 and $1.52 \%$ for untreated curaua and red pineapple fibers, respectively, and 2.11 and 1.1 or treated curaua and red pineapple fibers, respectively. Treated curaua show an increase in impurities over the untreated, supposedly caused by the removal of epidermal tissue from the fiber surface, which became the fiber bundle structure more accessible. FTIR spectra of the untreated, curaua and red pineapple fibers, showed shapes typical of lignocellulosic fibers and other PALF species studied. After pretreatment, FTIR of both fibers reveled a reduction mainly in peaks related to lignin $\left(\sim 1243 \mathrm{~cm}^{-1}\right)$, hemicelluloses and pectin $\left(\sim 1737 \mathrm{~cm}^{-1}\right)$. Treated curaua fibers also showed subtle transformations in bands related to cellulose and hemicellulose $\left(3330 \mathrm{~cm}^{-1}, 2900 \mathrm{~cm}^{-1}\right.$, $1103 \mathrm{~cm}^{-1}$ and $898 \mathrm{~cm}^{-1}$ ) and a reduction in wax-related peaks ( 2920 and $2850 \mathrm{~cm}^{-1}$ ), which can be also attributed to the removal of epidermal tissue from the fiber surface, leaving fibers more individualized the cellulose and hemicellulose layer more exposed.

The results of linear density evidence the effect of cottonization on reduction in the diameter of bundle fibers, which decreased by $30 \%$ (curaua) and $42 \%$ (red pineapple) after pretreatment. This contributed to increased breaking tenacity of treated fibers in a $12 \%$ (curaua) and $23 \%$ (red pineapple). Regarding dyeing performance, fibers dyed with blue, red and yellow reactive dyes revealed good color strength and an excellent color fastness to laundering. The $K / S$ values obtained (between 4 and 11 approx.) are compatible with textile application standards. These results suggest that the curaua and red pineapple were found to be two potential vegetable fibers for textile application.

Acknowledgements The authors gratefully acknowledge the funding by Support Foundation of the Institute for Technological Research, FIPT, Brazil, under Grants PCT 1059/17: FLORATEXTIL I; National Founds through FCT/MCTES, Portugal, under Grants UID/ CTM/00264/2019; Inovafil - Fiação, S.A., Portugal, under Grants "23958 - TSCY: Technical Staple Cellulosic Yarn."

Funding This work is also supported by FEDER funds through the Competitivity Factors Operational Programme-COMPETE and by national funds through FCT-Foundation for Science and Technology within the scope of the project POCI-01-0145-FEDER-007136.

\section{Compliance with ethical standards}

Conflict of interest The authors declare that they have no conflict of interest. 


\section{References}

1. Scheffer MR (2012) Trends in textile markets and their implications for textile products and processes. In: Shishoo R (ed) The global textile and clothing industry: technological advances and future challenges. Woodhead Publishing, Cambridge, pp 8-28

2. Ramawat KG, Ahuja MR (2016) Fiber plants: an overview. In: Ramawat KG, Ahuja M (eds) Fiber plants, sustainable development and biodiversity. Springer Nature, Cham, pp 3-15

3. Kozłowski RM, Muzyczek M (2017) Introduction. In: Kozlowski RM, Muzyczek M (eds) Natural fibers: properties, mechanical behavior, functionalization and applications. Nova Science Publishers, New York, $p$ vii- $x$

4. Kozłowski RM, Mackiewicz-Talarczyk M (2012) Introduction to natural textile fibres. In: Kozlowski RM (ed) Handbook of natural fibres: types, properties and factors affecting breeding and cultivation, vol 1. Woodhead Publishing, Cambridge, pp 1-8

5. Fletcher K (2014) Sustainable fashion and textiles, 2 nd edn. Routledge, London

6. Gardetti MA, Muthu SS (2015) The lotus flower fiber and sustainable luxury. Springer, Singapore, pp 3-18

7. Karthik T, Rathinamoorthy R, Ganesan P (2015) Sustainable luxury natural fibers-production, properties, and prospects. Springer, Singapore, pp 59-98

8. Debnath S (2015) Great potential of stinging nettle for sustainable textile and fashion. Springer, Singapore, pp 43-57

9. Debnath S (2016) Pineapple leaf fibre-a sustainable luxury and industrial textiles. Springer, Berlin, pp 35-49

10. Mittermeier RA, Robles-Gil P, Mittermeier CG (1997) Megadiversity: earth's biologically wealthiest nations. CEMEX, Mexico

11. Myers N, Mittermeier RA, Mittermeier CG, Fonseca GAB, Kent J (2000) Biodiversity hotspots for conservation priorities. Nature 403(6772):853-858

12. Medina JC (1959) Plantas fibrosas da flora mundial (Exc.). Seção de Plantas Fibrosas, Instituto Agronômico, Campinas

13. Sena Neto AR et al (2015) Comparative study of 12 pineapple leaf fiber varieties for use as mechanical reinforcement in polymer composites. Ind Crops Prod 64:68-78

14. Sena Neto AR, Araujo MAM, Souza FVD, Mattoso LHC, Marconcini JM (2013) Characterization and comparative evaluation of thermal, structural, chemical, mechanical and morphological properties of six pineapple leaf fiber varieties for use in composites. Ind Crops Prod 43(1):529-537

15. de Oliveira BF, Bolzan LT, Lima ÉP, Monteiro SN (2017) Performance of natural curaua fiber-reinforced polyester composites under $7.62 \mathrm{~mm}$ bullet impact as a stand-alone ballistic armor. J Mater Res Technol 6(4):323-328

16. Glória GO et al (2017) Tensile strength of polyester composites reinforced with PALF. J Mater Res Technol 6(4):401-405

17. Dickinson K (1986) Preparation. In: Preston C (ed) The dyeing of cellulosic fibres. Dyers' Company Publications Trust, London, pp 55-105

18. Kozłowski RM, Mackiewicz-Talarczyk M, Allam AM (2012) Bast fibres: flax. In: Kozłowski RM (ed) Handbook of natural fibres: types, properties and factors affecting breeding and cultivation. Woodhead Publishing, Cambridge, pp 56-113

19. Muzyczek M (2012) The use of flax and hemp for textile applications. In: Kozłowski Ryszard M (ed) Handbook of natural fibres: processing and applications. Woodhead Publishing, Cambridge, pp 312-328

20. Andrassy M, Pezelj E, Šurina R (2005) Improving the modification of tehnical flax fibers. In: Proceedings summary XIX. Croatian meeting of young chemists and chemical engineers

21. AATCC EP 6 (2018) AATCC Evaluation Procedure 6-2016, Instrumental Color Measurement. AATCC Technical Manual. American
Association of Textile Chemists and Colorists, Durham, pp 435-441

22. Berns RS (2019) Billmeyer and Saltzman's principles of color technology, 5th edn. Wiley, Hoboken

23. Trotman ER (1970) Dyeing and chemical technology of textile fibres, 4th edn. Charles Griffin \& Co., Ltd., New Jersey

24. Harwood J, Harwood R (2012) Testing of natural textile fibres. In: Kozłowski RM (ed) Handbook of natural fibres: types, properties and factors affecting breeding and cultivation. Woodhead Publishing, Cambridge, pp 345-390

25. ASTM D276-12 (2012) Standard test methods for identification of fibers in Textiles. ASTM International, West Conshohocken, $p$ 14

26. Gong J et al (2019) Investigation of the degradation of biorecalcitrance in Apocynum venetum fiber biodegumming. J. Nat. Fibers 16(1):1-12

27. Jabli M, Tka N, Ramzi K, Saleh TA (2018) Physicochemical characteristics and dyeing properties of lignin-cellulosic fibers derived from Nerium oleander. J Mol Liq 249:1138-1144

28. Morton WE, Hearle JWS (1997) Physical properties of textile fibres, 3rd edn. The Textile Institute, Manchester

29. Maluf $E$, Kolbe W (2003) Manual: dados técnicos para a indústria têxtil, 2nd edn. Instituto de Pesquisas Tecnológicas, São Paulo

30. ASTM D284 (2017) ASTM E284-17, Standard terminology of appearance. ASTM International, West Conshohocken, p 25

31. Choudhury AKR (2014) Instrumental measures of whiteness. In: Choudhury AKR (ed) Principles of colour and appearance measurement. Woodhead Publishing, Cambridge, pp 344-374

32. AATCC TM 110 (2018) AATCC Test Method 110-2015, Whiteness of textiles. American Association of Textile Chemists and Colorists, Durham, pp 185-186

33. Haque ANMA, Islam MA (2015) Optimization of bleaching parameters by whiteness index and bursting strength of knitted cotton fabric. Int J Sci Technol Res 4(4):40-43

34. Haque ANMA, Smriti SA, Hussain M, Farzana N, Siddiqa F, Islam MA (2018) Prediction of whiteness index of cotton using bleaching process variables by fuzzy inference system. Fash Text 5(1):4

35. Hossain MT, Hossain A, Saha PK, Alam MZ (2014) Effect of scouring and bleaching agents on whiteness index and bursting strength of cotton knitted fabric. Glob J Res Eng 19(1):22-28

36. ISO 105-J01 (1997) ISO 105-J01, Textiles-tests for colour fastness-Part J01: general principles for measurement of surface colour. International Organization for Standardization, Genève, p 13

37. Patel DR, Patel AL, Patel KC (2016) Colorimetric studies of some newly synthesized bisazo reactive dyes. Arab J Chem 9:S161-S169

38. Haggag K, El-Molla M, Mahmoued Z (2014) Dyeing of cotton fabrics using reactive dyes by microwave irradiation technique. Indian J Fibre Text Res 39:406-410

39. Jeyakodi Moses J, Radhika R (2012) Study of the K/S values, wash, light and rubbing fastnesses, and antimicrobial assessment on modal, cotton and modal/cotton (50:50) blended dyed fabrics. Appl Chem 46:8185-8188

40. Ingamells WC (1989) The influence of fibre structure on dyeing. In: Johnson A (ed) The theory of coloration of textiles, 2nd edn. Society of Dyers and Colourists, Brandford, pp 169-254

Publisher's Note Springer Nature remains neutral with regard to jurisdictional claims in published maps and institutional affiliations. 